\title{
Polyphenols treatment in patients with nonalcoholic fatty liver disease
}

\author{
Ludovico Abenavoli ${ }^{1}$, Natasa Milic ${ }^{2}$, Francesco Luzza ${ }^{1}$, \\ Luigi Boccuto ${ }^{3}$, Antonino De Lorenzo ${ }^{4}$ \\ 'Department of Health Sciences, University Magna Græcia, Campus Germaneto, \\ Viale Europa, 88100 Catanzaro, Italy; \\ 2Department of Pharmacy, University of Novi Sad, Hajduk Veljkova 3, 21000 Novi Sad, Serbia; \\ ${ }^{3}$ Greenwood Genetic Center, 113 Gregor Mendel Circle, 29646 Greenwood, SC, USA; \\ Clemson University School of Health Research, 101 Calhoun Drive, 29634 Clemson, SC, USA; \\ ${ }^{4}$ Division of Clinical Nutrition and Nutrigenomics, Department of Biomedicine and Prevention, \\ University Tor Vergata, via Montpellier 1, 00133 Rome, Italy
}

Address for Correspondence: Dr. Ludovico Abenavoli, M.D. Ph.D. Professor, Department of Health Sciences, University Magna Græcia, Viale Europa - Germaneto, 88100 , Catanzaro, Italy.

Email: I.abenavoli@unicz.it

\begin{tabular}{|l|}
\hline Access this article online \\
\hline $\begin{array}{l}\text { Website: } \\
\text { www.intern-med.com }\end{array}$ \\
\hline $\begin{array}{l}\text { DOI: } \\
\text { 10.1515/jtim-2017-0027 }\end{array}$ \\
\hline Quick Response Code: \\
\\
\\
\\
\\
\end{tabular}

\section{ABSTRACT}

Nonalcoholic fatty liver disease (NAFLD) affects $25-30 \%$ of the general population worldwide and this high prevalence is linked with lifestyle and dietetic changes, not only in Western countries, but also in the urban areas of developing countries. Several pharmacological approaches were proposed in the treatment of NAFLD, but the reported results are inconclusive. International guidelines recommended the reduction of dietary fat and fructose, in association with some physical activity. In this context, it was reported that the protective effects of traditional Mediterranean diet, related to the high concentration of antioxidant compounds, particularly of polyphenols. Polyphenols are a heterogeneous class of plant derived compounds, with some proven hepatoprotective effects. Our opinion is that the adherence to traditional Mediterranean diet characterized by the consumption of antioxidant-rich foods in general and of polyphenols in particular, can be considered as a potential new approach in the treatment of NAFLD.

Key words: nonalcoholic fatty liver disease, steatosis, polyphenols, Mediterranean diet, antioxidant

\section{INTRODUCTION}

In the last few decades, the term nonalcoholic fatty liver disease (NAFLD) has been evoked increasingly in research frameworks and in clinical practice. It defines the presence of significant fat accumulation in the liver (> $5 \%$ of hepatocytes), in the absence of alcohol abuse and any other cause of liver diseases. ${ }^{[1]}$ The term NAFLD includes different clinical entities, and in particular, the fat accumulation in liver, also known as simple fatty liver and nonalcoholic steatohepatitis (NASH); it is characterized by steatosis along with necroinflammation, fibrosis and finally cirrhosis with its complications. NAFLD is a pathological entity histologically characterized by the presence certain symptoms in the liver, such as cellular ballooning, lobular inflammation, perisinusoidal and perivenular fibrosis, features hardly distinguishable from the ones detected in cases with alcoholic liver disease. ${ }^{[2]}$ Insulin resistance, visceral fat mass, obesity, dyslipidemia, diabetes, and metabolic syndrome are well known risk factors largely associated to NAFLD. ${ }^{[3]}$ Studies on genetic and molecular mechanisms predisposed to NAFLD highlight the role of variants enhancing oxidative stress, pro-inflammatory profile of circulating cytokines, and abnormalities in the metabolism of glucose and fatty acids. ${ }^{[4,5]}$ NAFLD affects $25-30 \%$ of the general population; however, prevalence change in function of gender, age, ethnicity and metabolic features. ${ }^{[6]}$. The worldwide spread of NAFLD diagnosis is clearly linked with changes in dietary profiles and increased sedentary lifestyle, not only in Western countries but also in urban area of developing countries. ${ }^{[6]}$

Several pharmacological treatments have been proposed for the treatment of NAFLD, but the reported results are 
inconclusive. ${ }^{[7]}$ International recommendations indicate that the first therapeutic step for the treatment of NAFLD is to reduce the intake of total fat, saturated fatty acids, trans fatty acids and fructose, along with undergoing physical activity. ${ }^{[8]}$

\section{MEDITERRANEAN DIET}

The profile of NAFLD patients is characterized by higher dietary energy and higher simple carbohydrate intake, as compared with the healthy controls. ${ }^{[3,9]}$ The standard care to treat NAFLD patients is focused on lifestyle interventions, and in particular, healthy diet and physical exercise. In this way, literature has reported the benefits of Mediterranean diet. In November 2010, UNESCO officially recognized the Mediterranean diet as an Intangible Cultural Heritage of Humanity and defines it as a "set of traditional practices, knowledge and skills passed on from generation to generation, providing a sense of belonging and continuity to the concerned communities". ${ }^{[10]}$ Mediterranean diet is a way of eating, rather than a formal diet plan. The exact Mediterranean diet is difficult to define precisely, if considered that Mediterranean region is a virtual geographic area that represents many cultures and lifestyles. There are major differences in the dietetic profile between different countries and between some regions within a country, for example, as found in Italy. However, the traditional Mediterranean diet can be represented by a pyramid characterized by high consumption of cereals and vegetables, such as salads, pulses/legumes, bread, pasta, fruits and nuts, and lower intakes of eggs and sweets ${ }^{[11,12]}$ (Figure 1). Extra-virgin olive oil is the main source of fat with a moderate intake of fish, poultry, eggs and dairy products. In addition, moderate amounts of red wine are usually consumed with meals in the European region of the Mediterranean area. ${ }^{[13]}$

Adherence to the traditional Mediterranean diet is associated with low mortality risk and reduced incidence of chronic diseases, and in particular, cardiovascular and metabolic disorders, neurodegenerative diseases, depression and several types of cancer. ${ }^{[14,15]}$ These protective effects are related to the high concentration of antioxidants in compounds of this diet. Since the 1950s, Ancel Keys and his co-workers have been studying the Mediterranean diet effects on health, and they found that Greek people, especially belonging to the island of Crete, had the longest life expectancy in the world until the 1960s, followed by the people of Southern Italy, Spain and France. ${ }^{[16]}$ These data were confirmed by subsequent studies on the elderly population in Greece and other European Countries, and showed that the Mediterranean dietary pattern in toto influenced the longevity rather than a single nutrient in the diet, with a significant reduction in the overall mortality. ${ }^{[17]}$ This assumption is a cornerstone for public health, and in particular, in the context of prevention policy based on the Mediterranean style in the primary prevention of major chronic diseases not only in Western Countries, but also in all urban area worldwide. ${ }^{[18]}$

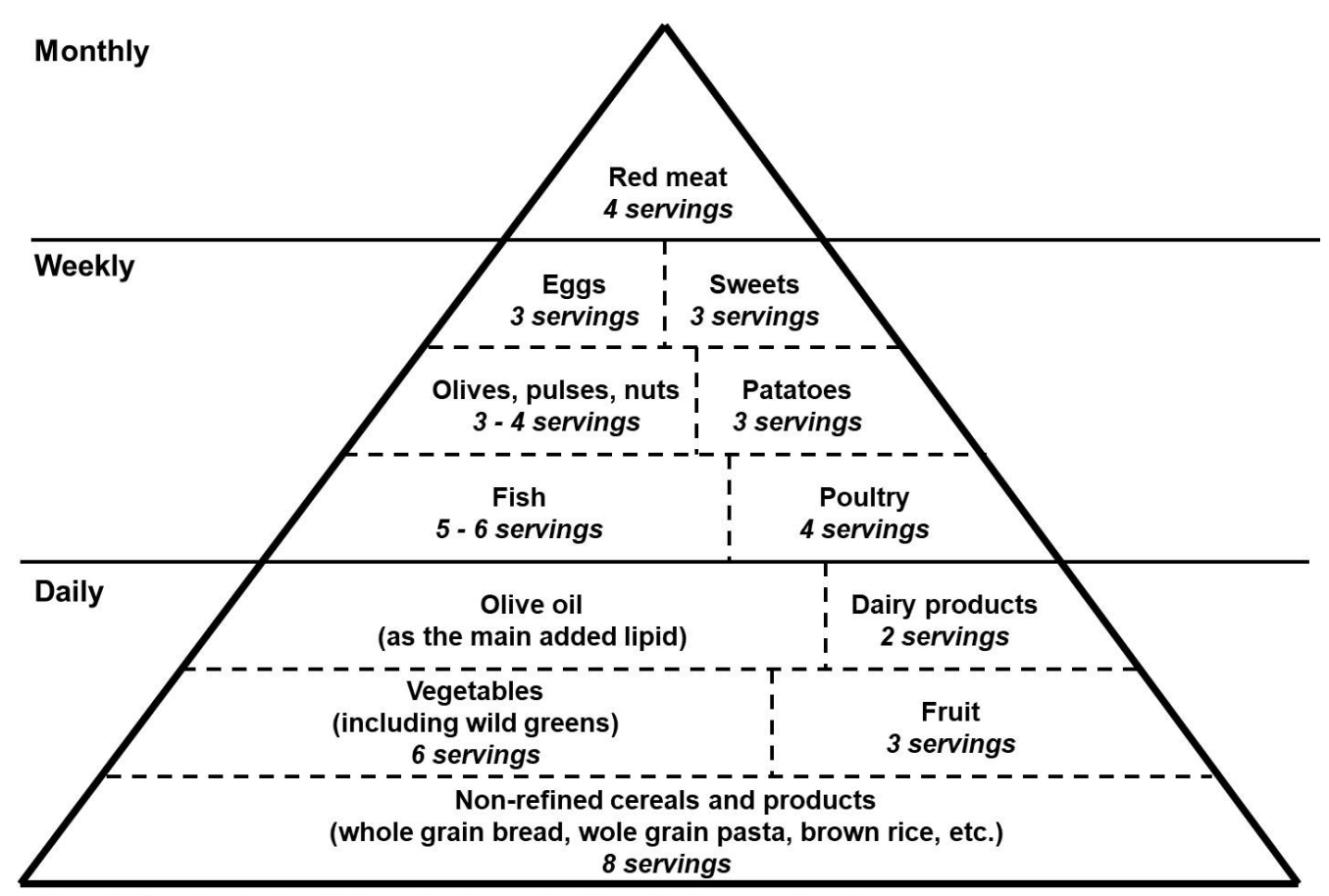

Also daily: physical activity; wine in moderation; 6 glasses of water

Figure 1: the traditional Mediterranean diet pyramid. 


\section{POLYPHENOLS AND NAFLD}

Polyphenols are a heterogeneous class of plant derived compounds, that include several hydro soluble antioxidants reported as health promoting agents and proposed in the treatment of different metabolic disorders. ${ }^{[19,20]}$ Fruits, vegetables, beverages including coffee, tea, red wine, and dark chocolate are the important sources of these bioactive compounds. On the basis of their chemical structure, two categories of polyphenols are described: the flavonoids containing a common diphenylpropane skeleton (e.g., flavonoids, flavones, flavanols, flavonols, isoflavones, proanthocyanidins and anthocyanins); the non-flavonoids, mainly comprising mono-phenols alcohols (e.g., hydroxytyrosol) or stilbene phenolic acids (e.g., resveratrol). ${ }^{[20]}$ In the short-term, polyphenols are not essential for life such as vitamins, however, nowadays they are considered responsible for the beneficial effects of fruits and vegetables. Their potential role in the prevention and treatment of oxidative stress and inflammation has been investigated recently. ${ }^{[21]}$ In particular, polyphenols may present hepatoprotective effects by increasing the fatty acid oxidation and modulation of insulin resistance, oxidative stress and inflammation, which are the main pathogenetic factors linked to the progression from simple fat accumulation to NASH. ${ }^{[20]}$ Several evidences in vitro, pre-clinical and emerging clinical trials reported beneficial effects on liver steatosis and its pathogenic and clinical setting. ${ }^{[20-23]}$

Few clinical studies were focused on the polyphenols use in NAFLD patients. Three were undertaken with $500 \mathrm{mg}$ and $600 \mathrm{mg}$ resveratrol daily for 12 weeks, or $3000 \mathrm{mg}$ daily for 8 weeks respectively. ${ }^{[24-26]}$ Other two studies were carried out using $150 \mathrm{mg}$ polyphenols (1.43\% of flavonoids, $2.5 \%$ anthocyanins and $1.7 \%$ phenolic acid) extract of Hibiscus sabdariffa L. or $1350 \mathrm{mg}$ of bayberry juice, daily for 12 weeks and 4 weeks in overweight and in young adults with NAFLD, respectively. ${ }^{[27,28]}$ Finally, one study utilized $250 \mathrm{~mL}$ of pomegranate juice or orange juice per day associated with hypocaloric diet over a period of 12 weeks. ${ }^{[29]}$ Some studies reported a significant impact of polyphenols' importance on NAFLD. Chang et al. and Ekhlasi et al. showed a significant improvement of anthropometric parameters after treatment with polyphenols. ${ }^{[27,29]}$ Faghihzadeh et al. observed a reduction in weight, body mass index, waist circumference, liver enzymes, and steatosis degree, while resveratrol was associated with lifestyle changes and particularly with physical activity. ${ }^{[24]}$ The reduction of serum transaminase levels was also noted by Chen et al. in association with a significant improvement of insulin resistance assessed by homeostasis model assessment insulin resistance index. ${ }^{[25]}$ The polyphenols used by humans through consumption of the bayberry juice and resveratrol showed anti-inflammatory effects, with a reduction in serum cytokines and in particular of TNF- $\alpha$, interelukin- 6 and -8 , and increased serum levels of adiponectin. ${ }^{[24,25,28]}$ In addition, Faghihzadeh et al. described a reduction in NF- $x \mathrm{~B}$ activity in the peripheral blood mononuclear cells. ${ }^{[2]}$ Finally, Ekhlasi et al. reported the reduction of high liver enzymes and improvement of total antioxidant capacity in the NAFLD patients treated with pomegranate juice. ${ }^{[29]}$ Nowadays, data on the effects of polyphenols in the histology of NAFLD, assessed by liver biopsy, are absent. However, the information obtained by non-invasive tools like the liver ultrasound reported a significant improvement of liver damage and liver steatosis degree when polyphenol supplementation is associated with lifestyle changes. ${ }^{[24,25,28]}$

\section{CONCLUSION}

NAFLD is the liver board of over nutrition and an upcoming challenge for hepatologists and health systems worldwide. Patients with liver steatosis have an increased prevalence of chronic diseases. Therefore, the treatment of NAFLD patients should be focused on reducing predisposing factors, such as insulin resistance, oxidative stress, and dyslipidemia. In this way, nutraceuticals may have an important role in the treatment of NAFLD. Supported by literature data, it can be concluded that adherence to the traditional Mediterranean diet characterized by the consumption of antioxidant-rich foods in general and of polyphenols in particular, can be considered as a potential new approach in the treatment of NAFLD, and even a valuable instrument of prevention of this disorder. Further studies are needed to define the achievable doses of individual polyphenols or select their combination.

\section{Conflict of Interest}

Authors declare no conflict of interest related to this publication.

\section{REFERENCES}

1. Nascimbeni F, Pais R, Bellentani S, Day CP, Ratziu V, Loria P, et al. From NAFLD in clinical practice to answers from guidelines. J Hepatol2013;59:859-71.

2. Kobyliak N, Abenavoli L. The role of liver biopsy to assess non-alcoholic fatty liver disease. Rev Recent Clin Trials 2014;9:159-69.

3. Abenavoli L, Milic N, Di Renzo L, Preveden T, Medić-Stojanoska M, De Lorenzo A. Metabolic aspects of adult patients with nonalcoholic fatty liver disease. World J Gastroenterol2016; 22:7006-16.

4. Anstee QM, DayCP. The genetics of NAFLD. Nat Rev Gastroenterol Hepatol 2013;10:645-55.

5. Severson TJ, Besur S, Bonkovsky HL. Genetic factors that affect nonalcoholic fatty liver disease: A systematic clinical review. World J Gastroenterol 2016; 22:6742-56.

6. Masarone M, Federico A, Abenavoli L, Loguercio C, Persico M. Non 
alcoholic fatty liver: epidemiology and natural history. Rev Recent Clin Trials 2014;9:126-33.

7. Italian Association for the Study of the Liver (AISF). AISF position paper on nonalcoholic fatty liver disease (NAFLD): Updates and future directions. Dig Liver Dis 2017;49:471-83.

8. European Association for the Study of the Liver (EASL); European Association for the Study of Diabetes (EASD); European Association for the Study of Obesity (EASO). EASL-EASD-EASO Clinical Practice Guidelines for the management of non-alcoholic fatty liver disease. J Hepatol2016; 64:1388-402.

9. Katsagoni CN, Papatheodoridis GV, Papageorgiou MV, Ioannidou P, Deutsch M, Alexopoulou A, et al. A "healthy diet-optimal sleep" lifestyle pattern is inversely associated with liver stiffness and insulin resistance in patients with nonalcoholic fatty liver disease. Appl Physiol Nutr Metab 2017;42(3):250-256 [PMID:28133993DOI:10.1139/apnm-2016-0492]

10. Available from: http://www.unesco.org/culture/ich/RL/00884

11. Abenavoli L, Milic N, Peta V, Alfieri F, De Lorenzo A, Bellentani S. Alimentary regimen in non-alcoholic fatty liver disease: Mediterranean diet. World J Gastroenterol 2014;20:16831-40.

12. Gelli C, Tarocchi M, Abenavoli L, Di Renzo L, Galli A, De Lorenzo A. Effect of a counseling-supported treatment with the Mediterranean diet and physical activity on the severity of the non-alcoholic fatty liver disease. World J Gastroenterol 2017;23:3150-62.

13. Di Renzo L, Carraro A, Valente R, Iacopino L, Colica C, De Lorenzo A. Intake of red wine in different meals modulates oxidized LDL level, oxidative and inflammatory gene expression in healthy people: a randomized crossover trial. Oxid Med Cell Longev 2014;2014:681318.

14. De Lorenzo A, Noce A, Bigioni M, Calabrese V, Della Rocca DG, Di Daniele N, et al. The effects of Italian Mediterranean organic diet (IMOD) on health status. Curr Pharm Des 2010; 16:814-24.

15. Sofi F, Abbate R, Gensini GF, Casini A. Accruing evidence on benefits of adherence to the Mediterranean diet on health: an updated systematic review and meta-analysis. AmJ ClinNutr2010; 92:1189-96.

16. Keys A, Menotti A, Aravanis C, Blackburn H, Djordevic BS, Buzina $\mathrm{R}$, et al. The seven countries study: 2,289 deaths in 15 years. Prev Med 1984; 13:141-54.

17. Di Daniele N, Noce A, Vidiri MF, Moriconi E, Marrone G, AnnicchiaricoPetruzzelli M, et al. Impact of Mediterranean diet on metabolic syndrome, cancer and longevity. Oncotarget 2017; 8:8947-79.
18. Schwingshackl L, Hoffmann G. Mediterranean dietary pattern, inflammation and endothelial function: a systematic review and meta-analysis of intervention trials. Nutr Metab Cardiovasc Dis 2014;24:929-39.

19. Del Ben M, Polimeni L, Baratta F, Pastori D, Angelico F. The role of nutraceuticals for the treatment of non-alcoholic fatty liver disease. $\mathrm{Br} \mathrm{J}$ Clin Pharmacol 2017; 83:88-95.

20. Rodriguez-Ramiro I, Vauzour D, Minihane AM. Polyphenols and nonalcoholic fatty liver disease: impact and mechanisms. Proc Nutr Soc 2016; 75:47-60.

21. Zhang PY. Polyphenols in Health and Disease. Cell BiochemBiophys2015; 73:649-64.

22. Salomone F, Godos J, Zelber-Sagi S. Natural antioxidants for nonalcoholic fatty liver disease: molecular targets and clinical perspectives. Liver Int2016; 36:5-20.

23. Van De Wier B, Koek GH, Bast A, Haenen GR. The potential of flavonoids in the treatment of non-alcoholic fatty liver disease. Crit Rev Food SciNutr2017;57:834-55.

24. Faghihzadeh F, Adibi P, Rafiei R, Hekmatdoost A. Resveratrol supplementation improves inflammatory biomarkers in patients with nonalcoholic fatty liver disease. Nutr Res 2014; 34:837-43.

25. Chen S, Zhao X, Ran L, Wan J, Wang X, Qin Y, et al. Resveratrol improves insulin resistance, glucose and lipid metabolism in patients with nonalcoholic fatty liver disease: a randomized controlled trial. Dig Liver Dis 2015; 47:226-32.

26. Chachay VS, Macdonald GA, Martin JH, Whitehead JP, O'Moore-Sullivan TM, Lee P, et al. Resveratrol does not benefit patients with nonalcoholic fatty liver disease. Clin Gastroenterol Hepatol 2014;12:2092-103.e1-6

27. Chang HC, Peng CH, Yeh DM, Kao ES, Wang CJ. Hibiscus sabdariffa extract inhibits obesity and fat accumulation, and improves liver steatosis in humans. Food Funct 2014; 5:734-9.

28. Guo H, Zhong R, Liu Y, Jiang X, Tang X, Li Z, et al. Effects of bayberry juice on inflammatory and apoptotic markers in young adults with features of nonalcoholic fatty liver disease. Nutrition 2014; 30:198-203.

29. Ekhlasi G, Shidfar F, Agah S, Merat S, Hosseini AF. Effects of Pomegranate and Orange Juice on Antioxidant Status in Non-Alcoholic Fatty Liver Disease Patients: A Randomized Clinical Trial. Int J Vitam Nutr Res 2016; 14: 1-7.

How to cite this article: Abenavoli L, Milic N, Luzza F, Boccuto L, De Lorenzo A. Polyphenols treatment in patients with nonalcoholic fatty liver disease. J Transl Intern Med 2017; 5: 144-47. 